\title{
QUEEN'S
UNIVERSITY
BELFAST
}

\section{Screening for the at-risk mental state in educational settings: A systematic review}

Howie, C., Potter, C., Shannon, C., Davidson, G., \& Mulholland, C. (2020). Screening for the at-risk mental state in educational settings: A systematic review. Early Intervention in Psychiatry, 14(6), 643-654.

https://doi.org/10.1111/eip.12926

\section{Published in:}

Early Intervention in Psychiatry

\section{Document Version:}

Peer reviewed version

Queen's University Belfast - Research Portal:

Link to publication record in Queen's University Belfast Research Portal

\section{Publisher rights}

(c) 2019 John Wiley \& Sons Australia, Ltd. This work is made available online in accordance with the publisher's policies. Please refer to any applicable terms of use of the publisher.

\section{General rights}

Copyright for the publications made accessible via the Queen's University Belfast Research Portal is retained by the author(s) and / or other copyright owners and it is a condition of accessing these publications that users recognise and abide by the legal requirements associated with these rights.

Take down policy

The Research Portal is Queen's institutional repository that provides access to Queen's research output. Every effort has been made to ensure that content in the Research Portal does not infringe any person's rights, or applicable UK laws. If you discover content in the Research Portal that you believe breaches copyright or violates any law, please contact openaccess@qub.ac.uk. 


\section{Screening for the At-Risk Mental State in Educational Settings: A Systematic Review}

Clare Howie $^{1}$, Claire Potter ${ }^{1}$, Ciaran Shannon ${ }^{2}$, Gavin Davidson $^{3}$, Ciaran Mulholland ${ }^{1} 2$

${ }^{1}$ Queen's University Belfast, School of Medicine. ${ }^{2}$ Northern Health and Social Care Trust, Antrim, UK. ${ }^{3}$ Queen's University Belfast, School of Social Sciences, Education and Social Work.

\section{Abstract}

Aim: The at-risk mental state allows clinicians to identify individuals who have an increased risk of developing psychosis. At present, most screening for psychosis-risk is carried out within help-seeking populations, however screening within educational settings may allow clinicians to identify individuals at-risk earlier and to increase the rate of detection. This review aimed to examine screening for the at-risk mental state in educational settings, with the key questions: what screening tools have been used in educational settings, can screening in educational settings detect individuals with ARMS, what threshold scores in screening tools indicate a positive screen in educational settings, are there comorbid mental health conditions associated with the ARMS in educational settings?

Methods: Searches were carried out in PsycINFO, MEDLINE, EMBASE, Scopus and Web of Science and reference lists of included articles searched. Results were summarised using narrative synthesis.

Results: Nine papers were included for narrative synthesis. A variety of screening tools have been used when screening for the at-risk mental state in educational settings. The majority of studies have been conducted in schools. The prevalence of the at-risk mental state reported in ranges from $1-8 \%$.

Conclusions: The at-risk mental state indicates the presence of distressing symptoms for which intervention may be beneficial. Screening programs within educational settings may allow outreach for prodromal symptoms at an earlier stage than clinical settings currently provide for.

Key words: psychosis, screening, at-risk mental state, attenuated symptoms, schools.

No of tables $=3$

No of figures $=1$

Word count $=5002$

Abstract $=224$ 


\section{Introduction}

Early intervention in psychosis can improve the prognosis of individuals who develop psychosis and if targeted in the prodromal stages, it can delay or prevent onset (Fusar-Poli et al., 2012). Researchers have been using the "at-risk mental state" (ARMS), also known as ultra-high-risk (UHR), clinical high-risk (CHR) or attenuated psychosis syndrome, to identify those at-risk of developing psychosis and intervene before first episode psychosis (Yung \& McGorry, 1996). The at-risk mental state is categorised by the presence of attenuated psychotic symptoms, brief limited intermittent psychotic symptoms, or trait vulnerability which must be accompanied by a decline in functioning over the previous twelve months. Evidence has indicated that detection and intervention for the at-risk mental state can be effective for reducing risk of transition and can improve prognosis for recovery for those who do develop psychosis (Fusar-Poli et al., 2013).

Screening is any approach which aims to determine if an individual is at a higher risk of developing a condition (National Health Service, 2018). Targeted screening is offered to individuals at a higher-risk of developing a condition and universal screening is offered to all individuals within certain populations. Once it is determined that an individual is at-risk, further diagnostic tests are carried out to confirm this. Screening tools can provide the opportunity to detect a condition at an earlier stage and provide intervention before the onset of further symptoms.

Duration of untreated psychosis (DUP) refers to the period which an episode of psychosis begins until the beginning of treatment for the episode (Norman \& Malla, 2001). For an individual affected by psychosis, the DUP is a key period which can have direct implications on the prognosis and recovery of an individual. Research has highlighted that reducing this timeframe is crucial for better outcomes, with longer periods of DUP being associated with poorer outcomes in terms of functioning, positive symptoms and quality of life (Marshall et al., 2005). Psychosis prevention and early intervention clinics provide the opportunity to reduce the DUP.

Screening for the at-risk mental state is generally carried out in help-seeking populations, with dedicated psychosis prevention and early intervention clinics being set up across the world (Broome et al., 2005; Yung et al., 2007). Psychosis prevention clinics may use screening measures, such as the Prodromal Questionnaire-16 (Ising et al., 2012), followed by a gold-standard assessment tool, such as the Comprehensive Assessment for the At-Risk 
Mental State (CAARMS) (Yung, Yuen, Phillips, Francey, \& McGorry, 2005) to detect and identify individuals at-risk.

Previous systematic reviews have examined screening for ARMS. Addington, Stowkowy, \& Weiser (2015) conducted a review of existing screening measures for clinical high risk, identifying 17 different screening measures. Their review identified that screening for ARMS is an area that has not been explored in detail and further research, particularly on the quality of these measures, should be conducted. Kline \& Schiffman (2014) conducted a review of self-report screening measures for psychosis-risk, from specialised clinical to general population samples. They highlighted the poor specificity of general population screening and low prevalence, and suggested that higher thresholds may be needed to reduce false positives. The Prodromal Questionnaire (Loewy, Bearden, Johnson, Raine, \& Cannon, 2005), Prodromal Questionnaire-Brief (PQ-B) (Loewy, Pearson, Vinogradov, Bearden, \& Cannon, 2011) and Prodromal Questionnaire-16 (PQ-16) were used in fourteen of the 34 studies included in their review and produced the most evidence for their 'screening utility'. Savill, D'Ambrosio, Cannon, \& Loewy (2018) focused their review on the Prodromal Questionnaire and its various iterations. They identified fourteen diagnostic accuracy studies, of which three of were conducted in non-help-seeking populations, including educational settings. These previous systematic reviews have not examined the role of screening for the at-risk mental state in educational settings which the current review aims to do.

While individuals may attend primary care settings to receive help for mental distress, this is not always the case. In their study of help-seeking preferences of young people in secondary schools in London, Leavey, Rothi, \& Paul (2011) found that young people were unsure about attending their primary care provider for mental health concerns and confused about disclosing confidential information while under the age of 16 . In this study, only $30 \%$ of young people stated they would attend their general practitioner if they were hearing voices. Other studies have found similar levels of reluctance from young people help-seeking for mental health distress (Zachrisson, Rödje, \& Mykletun, 2006). A systematic review of young people's perceived barriers to mental health help-seeking (Gulliver, Griffiths, \& Christensen, 2010) described stigma, embarrassment, and difficulty recognising mental health problems as some of the reasons given for not seeking help. These studies indicate that young people are reluctant to seek help for mental health difficulties from traditional gatekeepers and approaching young people directly may help with identifying distressing symptoms. 
Young people who need help the most may also be amongst the least likely to access it (Rickwood, Deane, Wilson, \& Ciarrochi, 2005). School environments provide an opening to offering screening programmes for young people (Rickwood, Deane, \& Wilson, 2007). A systematic review by Bradford \& Rickwood (2012) found that young people find it most acceptable to use self-reporting measures for psychosocial assessment, prior to face-to-face interviews with professionals. The application of self-report screening for ARMS can provide the opportunity to open dialogue between young people and professionals about distressing subthreshold psychotic symptoms.

Screening tools for ARMS have been identified as being suitably sensitive and specific to detect ARMS within individuals who are help-seeking or already engaging in services (Loewy, Bearden, Johnson, Raine, \& Cannon, 2005; Miller et al., 2003; Yung et al., 2005). Kline \& Schiffman (2014) highlighted the need for screening in large population-based samples to establish developmentally-sensitive norms for screening tools.

For this review, educational settings have been defined as a setting in which individuals within the age-range for ARMS (ages 14 - 35 years) would attend for educational purposes: schools (secondary/middle/high) which include individuals aged $14-18$ years, further education colleges which include individuals aged over 16 years, and university settings which typically include individuals aged 18 years onwards.

This paper presents a systematic review examining screening methods used to detect individuals with the at-risk mental state. The review specifically aims to answer the following:

1. What screening tools have been used in educational settings?

2. Can screening in educational settings detect individuals with ARMS? This is addressed by examining what percentage of those screened scored above the cut-off threshold and how many individuals above the thresholds were found to be at-risk of developing psychosis?

3. What threshold scores in screening tools indicate a positive screen in educational settings?

4. Are there comorbid mental health conditions associated with the ARMS in educational settings? 


\section{Methods}

\subsection{Protocol}

A study protocol was registered on Prospero and can be accessed on their database (ID: CRD42018091799).

\subsection{Search Method}

An electronic search of PsycINFO, MEDLINE, EMBASE, Scopus and Web of Science was carried out on 11 April 2018 and rerun on databases on 19 July 2018 and 28 May 2019. The searches aimed to find any articles that detailed screening procedures for the at-risk mental state carried out within educational settings. No limitations were set on database searches to ensure all relevant articles were identified. The search strategy was developed using pearl harvesting techniques (Sandieson, 2006). The following search strategy was used with three key parameters:

(1) at-risk mental state,

(2) screening tools and

(3) educational settings.

Search terms for the at-risk mental state: "at risk mental state" OR "ultra high risk" OR “clinical high risk” OR (psycho* adj3 prodrom*) OR “attenuated psycho* symptom*” OR “attenuated psycho* syndrome” OR "basic symptom*” AND search terms for screening tools: Screen* OR detect* OR assess* OR "self* report*” OR question* AND search terms for educational settings: Adolescent* OR Youth* OR Student* OR Education* OR School* OR "Junior high" OR "Middle school" OR “Post*primary” OR "high school*” OR college* OR universit* OR “secondary school*”. Hand searches were carried out on the reference lists of included articles to identify relevant articles which had not been identified by the electronic searches.

All references from database searches were exported onto Covidence (Veritas Health Innovation) and duplicates were removed.

\subsection{Eligibility Criteria and Selection}

Studies included were those in which screening was carried out on individuals in educational settings that comprise the age-range ( 14 - 35 years) for ARMS; this included secondary-level 
schools, universities and colleges. All study types were included. Studies examining individuals already engaged in mental health clinical services were excluded. There were no restrictions on screening tools for the at-risk mental state. Studies were only included if they were available in English. At full-text screening, studies which did not include a follow-up validation measure (e.g. CAARMS, SIPS) to confirm the presence of the at-risk mental state were excluded. This criterion was added to ensure included studies examined ARMS specifically and ARMS status was confirmed.

Interrater agreement at title and abstract stage $(\kappa=0.5)$ was moderate and agreement at fulltext stage $(\kappa=0.6)$ was moderate (based on ranges set by Landis \& Koch, 1977). There was minor disagreement on 92 title/abstract decisions (95\% agreement) and nine full-text decisions (91\% agreement). Conflicts were resolved with discussion between the two reviewers with inclusion with the study team, when necessary.

Quality of included texts were completed independently by $\mathrm{CH}$ and $\mathrm{CP}$ and assessed using the Standard Quality Assessment Criteria for Evaluating Primary Research Papers from a Variety of Fields (Kmet, Lee, \& Cook, 2004).

\subsection{Data Extraction}

Data extraction was completed using a standardised data extraction form by $\mathrm{CH}$. Data extracted included the following:

- Information on educational settings used for screening.

- Participant demographics.

- Descriptive information on the screening tools employed, assessment measures used to validate screening tools, sensitivity and specificity of screening tools, cut-off scores of tools.

- Demographic information on those identified as having an at-risk mental state through screening procedures. 


\section{Results}

The Preferred Reporting Items for Systematic Reviews and Meta-Analyses (PRISMA; Moher et al., 2009) flowchart in Figure 1 details the process of study selection.

\section{INSERT FIGURE 1 HERE}

\subsection{Summary of articles}

Nine full-texts were included for final discussion (Table 1) which detailed eight studies; two papers described the same study (Chen et al., 2016; Chen et al., 2014). Four of the included studies examined validation of screening tools in non-clinical populations, using educational settings. The remaining four studies examined the presentation of ARMS in educational settings, using screening as a means of identifying those at-risk.

Studies were conducted between 2004 and 2019, with most studies being conducted in Korea $(\mathrm{n}=4)$, other studies were conducted in China $(\mathrm{n}=1)$, Republic of Ireland $(\mathrm{n}=1)$, Nigeria $(\mathrm{n}=1)$ and Republic of Palau $(n=1)$. Seven of the eight studies were conducted in urban settings, while the study conducted in Palau was an isolated island community setting. Five screening measures were identified from included studies. All of the included studies employed quantitative methods. The sample sizes of the included studies ranged from 508 to 3400 .

All of the included studies used a universal screening approach, with the exception of Chung et al (2013). They initially screened all participants $(n=1002)$ with the Korean Youth SelfReport (K-YSR), then implemented targeted screening using the Eppendorf Schizophrenia Inventory (ESI) on $n=217$, for those who scored equal to or higher than the cut-off of the KYSR.

\subsubsection{Sample characteristics}

The age range of participants from included studies varied from 11 years up to 36 years. Three included studies did not state the age range of participants. Okewole et al. (2015) included young people from $10^{\text {th }}$ to $12^{\text {th }}$ grade in secondary schools in Nigeria. Kim and colleagues (2018) included college students aged 18 years onwards, and Ord et al. (2004) included high school students, but did not state any further age information. 


\subsubsection{Quality of included studies}

Both reviewers assigned the same quality score to six papers, with scores differing on three papers. Differences in scoring was due to differences in assigning 'yes' and 'partial' in items relating to clarity of the research question and sufficient detail of the results.

Okewole et al (2015) and Ord, Myles-Worsley, Blailes, \& Ngiralmau (2004) were rated low for quality, due to the lack of information that was presented in their texts; they did not present adequate information on participant's characteristics, reporting of estimates of variance, and presenting results in sufficient detail. This may be attributed to limited space available to present information as both papers were presented as letters to the editor.

\section{INSERT TABLE 1 HERE}

\subsection{Tools used in educational settings}

\subsubsection{The Prodromal Questionnaire-16 (PQ-16). The PQ-16 (Ising et al., 2012) was} developed from the Prodromal Questionnaire (Loewy, Bearden, Johnson, Raine, \& Cannon, 2005). The $P Q$ is a 92-item screening measure validated for use in clinical populations, the PQ-16 is a 16-item measure using questions from the PQ, but in a reduced format for ease of use. The PQ-16 consists of three subscales; perceptual abnormalities/hallucinations, unusual thought content, and negative symptoms. The PQ-16 consists of both a symptom scale - True or False, and a distress scale. The distress scale runs as True with no distress' (scored as 0), True with mild distress (scored as 1), True with moderate distress (scored as 2) and True with severe distress (scored as 3 ). A symptom score of $\geq 6$ has been endorsed for use in helpseeking populations.

3.2.2. The Prodromal Questionnaire-Brief (PQ-B). The PQ-B (Loewy, Pearson, Vinogradov, Bearden, \& Cannon, 2011) was developed as a shorter version of the original Prodromal Questionnaire (Loewy et al., 2005), consisting of 21 items. It consists of a total score scale ( sum of all 21 items with Yes $=1, \mathrm{No}=0$ ), and a distress score scale (from No to Strongly Agree). The creators of the PQ-B endorse a cut-off total score of $\geq 6$.

3.2.3. The Adolescent Psychotic Symptom Screener (APSS). The APSS (Kelleher, Harley, Murtagh, \& Cannon, 2011) is a 7-item screener consisting of four items from the Diagnostic 
Interview Schedule for Children and three questions on visual hallucinations, delusions of control and grandiosity. The questions have three responses; 'Yes definitely' (scored as 1), 'Maybe' (scored as 0.5 ) and 'No (scored as 0 ). The authors endorsed a score of $\geq 2$ as an indicator of an individual possibly at-risk of developing psychosis.

3.2.4. The Eppendorf Schizophrenia Inventory (ESI). The ESI was developed as a screening measure based on subjective experiences of symptoms by individuals with schizophrenia (Mass, 2000). The ESI is comprised of four subscales; Attention and Speech Impairment, Ideas of Reference, Auditory Uncertainty, Deviant Perception. Questions are rated on a 4point scale from ranking from 'absolutely true' $=3$ to 'not true at all' $=0$. A cut-off score of $\geq 29$ has been previously endorsed.

3.2.5. The Youth Psychosis At-Risk Questionnaire (Y-PARQ). The Y-PARQ is a 92-item screening measure based on the CAARMS (Yung et al., 2005). Responses are 'Yes' (scored as 1) or 'No/Unsure' (scored as 0). The Y-PARQ assesses positive, negative and affective symptoms of psychosis. A cut-off score of $\geq 11 / 24$ items on the positive subscale is endorsed for further follow-up.

3.3. Detection of the at-risk mental state in educational settings

\section{INSERT TABLE 2 HERE}

The rate of individuals scoring above the threshold score on the screening measures varied from $9.6 \%$ to $33.6 \%$. Some of the studies used the recommended cut-off scores for the screening measures (Chen et al., 2016), whereas other studies used a lower cut-off threshold (Kim et al., 2018) which may be a contributing factor on the range of the samples scoring above threshold.

Five of the eight studies stated their prevalence rates of ARMS from their total sample screened. Prevalence rates of ARMS in young people in educational settings, when screened and assessed using gold-standard assessment criteria for the at-risk mental state (e.g. SIPS, CAARMS), ranged from 0.9 to $8.1 \%$. It is likely that the variation in the range of prevalence depended on the criteria and assessment tools used. For example, Kelleher et al (2012) reported $8.1 \%$ of their follow-up sample had met criteria for psychosis-risk syndrome; this was when Structured Interview for Prodromal Syndromes (SIPS) criteria was used. In the 
same sample, using CAARMS criteria, without applying the decline in functioning, $7.7 \%$ met the criteria. However, when CAARMS criteria was used along with a $30 \%$ decline in functioning, only $0.9 \%$ of individuals in their sample met the criteria for ARMS. Ord et al. (2004) did not report a prevalence rate, but at the time of their publication, 61 participants from their sample had been identified as being at-risk of developing psychosis.

3.4. Threshold scores used in educational settings

\section{INSERT TABLE 3 HERE}

Optimal cut-off scores were specified by the studies as those that balanced the greatest sensitivity with the greatest specificity. Four of the eight included studies examined the validity of screening tools using an educational setting-based population. Chen et al. (2016) used the recommended cut-off score of $\geq 6$ for the CPQ-16 on the symptom score, however they found that $\geq 9$ on the distress score was the optimal cut-off for identifying those at-risk in a college population. Kim et al. (2018) used a lower cut-off score of $\geq 4$ for the KPQ-16 on the symptom score to ensure they identified as many individuals at-risk as possible. They also found a higher cut-off score ( $\geq 7$ on the symptom score) produced an optimal cut-off point for further assessment in a college population. In help-seeking populations, a cut-off total score of $\geq 7$ has been previously endorsed (Savill, D'Ambrosio, Cannon, \& Loewy, 2017), however Okewole et al. (2015) found that a total score of $\geq 8$ on the PQ-B in their secondary school population produced the greatest sensitivity and specificity. Okewole et al. (2015) did not provide details on the values for sensitivity, specificity or positive predictive values for their cut-off scores. Jang et al (2019) found that a total score of $\geq 7$ and a distress score of $\geq 22$ produced sensitivity and sensitivity of $>70 \%$, however the distress score had a greater positive predictive value $(\mathrm{PPV}=14.1 \%)$ than total score $(\mathrm{PPV}=11.7 \%)$.

\subsection{Comorbidity with the at-risk mental state in educational settings.}

Three of the eight included studies examined the presentation of ARMS in populations based in educational settings. As part of examining ARMS, they observed comorbid mental health conditions utilising other assessment tools. Two of the studies (Kelleher et al., 2012; Kim et al., 2018), assessed the presence of depressive disorder with ARMS. Kelleher (2012) reported $37 \%$ of those identified as being at-risk also fulfilled criteria for depressive disorder, while 
Kim et al (2018) reported $25 \%$ of the ARMS sample also could be diagnosed with depressive disorder. However, Kim et al (2018) found no significant difference between the rate of depressive disorder in their at-risk and non-at-risk population for depressive disorder. Kelleher et al (2012) reported that anxiety disorder was also demonstrated in $32 \%$ and behavioural disorders in $21 \%$ of those with ARMS in their sample. Chen et al. (2014) found depression and anxiety, as assessed by the Symptom Checklist-90, were significantly associated with psychosis-risk symptoms. Chen et al. (2014) also found that $30 \%$ of the individuals with ARMS in their sample reported having experienced parental divorce, which they found to be significantly higher than in those without ARMS. 


\section{Discussion}

\subsection{Main results}

This review aimed to answer four key questions: what screening tools have been used in these settings, can screening in educational settings detect individuals with ARMS, what threshold scores in screening tools indicate a positive screen in educational settings, and are there comorbid mental health conditions associated with the ARMS in educational settings?

A number of screening tools were employed in the included studies, with the most common being either the PQ-16 or PQ-B (used in three of the eight studies). Previous systematic reviews (Kline \& Schiffman, 2014; Savill et al., 2017) have identified that the Prodromal Questionnaire (in its various iterations) is a screening measure that has been validated for use in different populations and is accurate in predicting possible at-risk mental states. The current review is unable to determine whether the PQ is the most suitable screening measure or if there is a more suitable measure that could be used for screening within educational settings.

The percentage of individuals who scored above the screening measure threshold scores varied from $9.6 \%$ to $40 \%$. This variation may be due to both the screening measures used and the thresholds employed in the studies or it may be due to real differences in frequency. Chen et al. $(2014 ; 2016)$ used the recommended cut-off score of $\geq 6$ for the PQ-16 which $9.6 \%$ of their sample met. However, using the PQ-16, Kim et al (2018) set a lower cut-off score of $\geq 4$ which $23.1 \%$ of their sample met. From the included studies, we can determine that screening was able to detect individuals at-risk of developing psychosis in educational settings, although there appears to be a low prevalence rate of this in an educational population setting. Low prevalence rates for the at-risk mental state in non-help-seeking populations are typical (Savill et al., 2018) and this is reflected in the rates reported in this review.

This review also identified that higher-than-recommended threshold scores produced greater balance between sensitivity and specificity when screening in educational setting populations. In all the included studies that examined threshold scores, higher threshold scores demonstrated a greater balance, regardless of the screening tools used. To reduce the rate of false positives, future research on screening for the at-risk mental state in educational settings may consider employing higher cut-off thresholds. This review is unable to recommend particular cut-offs for screening tools in educational settings at this time, future research should address this. 
Three of the included studies highlighted the comorbidity of other mental health conditions that were associated with the presence of the at-risk mental state. This concurs with previous research that has identified that individuals at-risk of psychosis tend to also present with affective disorders (i.e. depression, anxiety). Research examining the reasons for helpseeking from individuals at-risk of developing psychosis or those with first-episode psychosis have identified that individuals are more likely to seek help for affective symptoms rather than psychotic experiences (Addington, Van Mastrigt, Hutchinson, \& Addington, 2002; Falkenberg et al., 2015).

\subsection{Implications}

Obuchowski et al. (2001) outlined their ten criteria for effective screening, for which it could be argued that psychosis-risk screening in educational settings fulfils many of these criteria and has the potential to reduce the transition to psychosis. There is concern that screening outside help-seeking and clinical populations can label individuals as at-risk of developing psychosis when this is not the case. Savill, D’Ambrosio, Cannon, \& Loewy (2017) exercise caution at recommending screening in community settings, as this can increase the chance of detecting false positives and reducing the accuracy of the at-risk mental state as a diagnostic model. They do acknowledge that further efforts need to be undertaken to identify and reach out to young people.

While there are concerns around exposing young people to a mental health label, there may be benefits to screening for ARMS. Screening within educational settings could provide opportunities to use large population-based samples, targeting the age-range for ARMS, and allow clinicians to make young people aware of services available to them if they are experiencing symptoms.

Chen et al. (2014), Kelleher et al. (2012) and Kim et al. (2018) identified comorbid mental health disorders with ARMS in educational settings. Those examining individuals at-risk of developing psychosis in educational settings may wish to consider the comorbidity and the increased likelihood of seeking help for these symptoms.

While screening was able to detect individuals at-risk from the included studies, the low prevalence rate in this population makes it difficult to justify universal screening, considering the potential costs for schools and clinics. There is the concern that applying ARMS criteria to groups with a lower risk of psychosis may 'dilute' the prognostic accuracy of the construct (Fusar-Poli, 2017). Targeted screening programmes for the at-risk mental state in educational 
settings may provide a more feasible option for identifying individuals at-risk of psychosis in these settings and reduce the potential dilution of the paradigm.

In five of the eight studies, the authors highlighted the importance of further follow-up or longitudinal research to examine the transition rates to psychosis for individuals found to be at-risk of developing psychosis in educational settings when compared to clinical settings. The long-term outcomes of individuals with ARMS identified through screening in schools and colleges are unknown, and further research could aim to identify the prognosis of these individuals.

\subsection{Limitations}

None of the studies examined the longitudinal outcomes of the individuals identified as having ARMS and the rate of transition to first-episode psychosis is unknown in this group. It is not possible to determine if there are any predictors among this group for transitioning to first-episode psychosis. The included studies used a follow-up assessment measure after a screening measure to determine the at-risk status of participants. However, different followup assessment measures were used across studies (i.e. SIPS, CAARMS, K-SADS). This strongly suggested that reporting of different prevalence rates depended on assessment criteria used (Kelleher et al., 2012).

The majority of studies were conducted in urban settings. Previous research has indicated that prevalence of psychosis increases with urbanicity (Allardyce et al., 2008; Marcelis, NavarroMateu, Murray, \& van Os, 1998; van Os, Hanssen, Bijl, \& Vollebergh, 2003). The rates of the presence of the at-risk mental state in educational settings that were examined in the included studies may not be reflective of rural environments. The one included study that was not conducted in an urban environment could be argued to not be reflective of potential prevalence rates elsewhere. Ord, Myles-Worsley, Blailes, \& Ngiralmau (2004) noted that one of the purposes of conducting screening for the at-risk mental state in Palau was due to the 'elevated rate of familial schizophrenia' occurring in this small island nation (population, 21,000). Prevalence rates reported from studies conducted in educational settings may only be reflective of urban environments. Further research may wish to examine if there is a difference between rural and urban educational populations.

It is key that individuals who are identified as at-risk through school screening programmes are able to access appropriate psychological therapies. Appropriate support should be available to all individuals screened and appropriate services available for individuals who 
meet the criteria for ARMS. Ensuring educational settings have adequate resources to provide appropriate care and support to young people at-risk of developing psychosis is necessary when planning screening within these settings (Levitt, Saka, Hunter Romanelli, \& Hoagwood, 2007). In a survey of school-based mental health professionals, Kline, Chokran, Rodenhiser-Hill, Seidman, \& Woodberry (2019) identified that these professionals rated themselves as being significantly less confident providing treatment for psychosis, which may impede on screening. Professionals in these settings carrying out psychosis-risk screening should undergo suitable training to build confidence in carrying out screening and offering intervention.

There is reasonable concern with the possibility of labelling individuals with a 'diagnosis' of ARMS (Kamens, Elkins, \& Robbins, 2017), with the poor predictive validity of transition to psychosis for those labelled at-risk (van Os \& Guloksuz, 2017). The studies do not examine the stigma that may be associated with a label of being at-risk of developing psychosis. Further work needs conducted on the stigma attached to this label and what can be done to reduce stigmatisation (Yung et al., 2012). In their study of young people at-risk of developing psychosis, Byrne \& Morrison (2010) identified that young people reported being reluctant to report their psychotic-like experiences due to fear of negative reactions. Particularly in the context of educational settings, future research may wish to examine the potential harm that having a label of being 'at-risk' of developing psychosis may have.

The included studies in this review were conducted in a diverse range of countries, and stigma can be a major barrier to help-seeking particularly in low and middle-income countries (Mascayano, Armijo, \& Yang, 2015). The use of screening for ARMS in educational settings should be given careful consideration depending on the context in which it is being employed. History has shown how psychiatry has been abused for political reasons, particularly the label of psychosis, and continues to be used for harmful purposes in countries with a history of human rights abuses (Van Voren, 2010).

\section{Conclusions}

The review has shown that screening for the ARMS has been conducted within educational settings and the rate of individuals at-risk of psychosis in these settings vary. There is a wide range of individuals who score above the threshold scores in screening measures when used in educational settings. 
This review highlights the differences in cut-off scores for screening measures used in educational settings. Future studies examining screening for ARMS may wish to employ higher cut-off scores when using screening measures to avoid a high rate of false positives. All of the included studies used at least a two-stage process for identifying those at-risk of developing psychosis; it is recommended that screening should be followed up with a gold standard assessment measure to confirm the presence of the at-risk mental state in an individual.

The long-term outcomes of individuals with ARMS identified through screening in schools and colleges are unknown, and further research could aim to identify the prognosis of these individuals.

For professionals seeking to implement screening for ARMS in educational settings, at present there is no tool that could be recommended over another tool. While it is not possible to make a specific recommendation regarding cut-off scores on any of the relevant tools, in general this review would support the adoption of higher cut-off scores than are used in clinical populations. There has been no research done on targeted screening in this setting. The studies included have all used universal screening which detects relatively few cases for a time and financially costly process. Targeted screening may be beneficial in this setting. In terms of number of individuals eligible for services, this review has shown that potentially between 1 and $8 \%$ of individuals would be eligible for ARMS services. Targeted screening may detect the majority of these cases but with less use of resources.

Screening for ARMS in educational settings could enable individuals at-risk to access interventions earlier and alleviate distressing symptoms earlier, however caution should be exercised with rolling out screening programmes to young people.

\section{Contributors}

Clare Howie conducted the searches, screening and data extraction, and wrote the manuscript. Claire Potter conducted screening at abstract and full-text stages and assisted with the development of the protocol. Ciaran Shannon, Ciaran Mulholland and Gavin Davidson developed the concept for the study, provided input at all stages of the study and contributed to the completion of the manuscript.

\section{Conflict of Interest}

All authors declare they have no conflicts of interest. 
Page $\mathbf{1 7}$ of $\mathbf{3 0}$

\section{Acknowledgment}

This work was conducted as part of Clare Howie's PhD project, a studentship funded by the Northern Ireland Department for the Economy. 


\section{References}

Addington, J., Stowkowy, J., \& Weiser, M. (2015). Screening tools for clinical high risk for psychosis. Early Intervention in Psychiatry, 9(5). https://doi.org/10.1111/eip.12193

Addington, J., Van Mastrigt, S., Hutchinson, J., \& Addington, D. (2002). Pathways to care: help seeking behaviour in first episode psychosis. Acta Psychiatrica Scandinavica, 106(5), 358-364. Retrieved from http://www.ncbi.nlm.nih.gov/pubmed/12366470

Allardyce, J., Gilmour, H., Atkinson, J. ., Rapson, T., Bishop, J., \& McCreadie, R. . (2008). Social fragmentation, deprivation and urbanicity: relation to first-admission rates for psychoses. British Journal of Psychiatry, 187, 401-406.

Bradford, S., \& Rickwood, D. (2012). Psychosocial assessments for young people: a systematic review examining acceptability, disclosure and engagement, and predictive utility. Adolescent Health, Medicine and Therapeutics, 111. https://doi.org/10.2147/ahmt.s38442

Broome, M. R., Woolley, J. B., Johns, L. C., Valmaggia, L. R., Tabraham, P., Gafoor, R., ... McGuire, P. K. (2005). Outreach and support in south London (OASIS): Implementation of a clinical service for prodromal psychosis and the at risk mental state. European Psychiatry, 20(5-6), 372-378. https://doi.org/10.1016/j.eurpsy.2005.03.001

Byrne, R., \& Morrison, A. P. (2010). Young people at risk of psychosis: A user-led exploration of interpersonal relationships and communication of psychological difficulties. Early Intervention in Psychiatry, 4(2), 162-168. https://doi.org/10.1111/j.17517893.2010.00171.x

Chen, F., Wang, L., Heeramun-Aubeeluck, A., Wang, J., Shi, J., Yuan, J., \& Zhao, X. (2014). Identification and characterization of college students with Attenuated Psychosis Syndrome in China. Psychiatry Research, 216(3), 346-350.

https://doi.org/10.1016/j.psychres.2014.01.051

Chen, F., Wang, L., Wang, J., Heeramun-Aubeeluck, A., Yuan, J., \& Zhao, X. (2016). Applicability of the Chinese version of the 16-item Prodromal Questionnaire (CPQ-16) for identifying attenuated psychosis syndrome in a college population. Early Intervention in Psychiatry, 10(4), 308-315. https://doi.org/https://dx.doi.org/10.1111/eip.12173

Chung, Y.-C., Kang, N.-I., Im, Y.-J., Kim, S.-W., Cho, I. H., Lee, Y. M., \& Kwon, J. S. (2013). Validation of the Korean version of the Eppendorf Schizophrenia Inventory as a 
screening measure to detect adolescents at ultra-high risk for psychosis. Early Intervention in Psychiatry, 7(1). https://doi.org/10.1111/j.1751-7893.2012.00363.x

Falkenberg, I., Valmaggia, L., Byrnes, M., Frascarelli, M., Jones, C., Rocchetti, M., ... FusarPoli, P. (2015). Why are help-seeking subjects at ultra-high risk for psychosis help-seeking? Psychiatry Research, 228(3), 808-815. https://doi.org/10.1016/j.psychres.2015.05.018

Fusar-Poli, P. (2017). The clinical high-risk state for psychosis (CHR-P), Version II. Schizophrenia Bulletin, 43(1), 44-47. https://doi.org/10.1093/schbul/sbw158

Fusar-Poli, P., Bonoldi, I., Yung, A. R., Borgwardt, S., Kempton, M. J., Valmaggia, L., ... Mcguire, P. (2012). Predicting Psychosis: Meta-analysis of Transition Outcomes in Individuals at High Clinical Risk. Archives of General Psychiatry, 69(3), 220-229. https://doi.org/10.1001/archgenpsychiatry.2011.1472

Fusar-Poli, P., Borgwardt, S., Bechdolf, A., Addington, J., Riecher-Rössler, A., SchultzeLutter, F., ... Yung, A. (2013). The Psychosis High-Risk State. JAMA Psychiatry, 70(1), 107. https://doi.org/10.1001/jamapsychiatry.2013.269

Gulliver, A., Griffiths, K. M., \& Christensen, H. (2010). Perceived barriers and facilitators to mental health help-seeking in young people: A systematic review. BMC Psychiatry, 10(10). https://doi.org/10.1186/1471-244X-10-113

Ising, H. K., Veling, W., Loewy, R. L., Rietveld, M. W., Rietdijk, J., Dragt, S., ... Van Der Gaag, M. (2012). The validity of the 16-item version of the prodromal questionnaire (PQ-16) to screen for ultra high risk of developing psychosis in the general help-seeking population. Schizophrenia Bulletin, 38(6). https://doi.org/10.1093/schbul/sbs068 Jang, Y. E., Lee, T. Y., Hur, J.-W., \& Kwon, J. S. (2019). Validation of the Korean Version of the Prodromal Questionnaire-Brief Version in Non-Help-Seeking Individuals. Psychiatry Investigation, 16(2), 109-114. https://doi.org/http://dx.doi.org/10.30773/pi.2018.10.23

Kamens, S. R., Elkins, D. N., \& Robbins, B. D. (2017). Open Letter to the DSM-5. Journal of Humanistic Psychology, 57(6), 675-687. https://doi.org/10.1177/0022167817698261

Kang, N. I., Park, T. W., Yang, J. C., Oh, K. Y., Shim, S. H., \& Chung, Y. C. (2012). Prevalence and clinical features of Thought-Perception-Sensitivity Symptoms: Results from a community survey of Korean high school students. Psychiatry Research, 198(3), 501-508. https://doi.org/10.1016/j.psychres.2012.03.005 
Kelleher, I, Murtagh, A., Molloy, C., Roddy, S., Clarke, M. C., Harley, M., \& Cannon, M. (2012). Identification and Characterization of Prodromal Risk Syndromes in Young Adolescents in the Community: A Population-Based Clinical Interview Study. Schizophrenia Bulletin, 38(2), 239-246. https://doi.org/10.1093/schbul/sbr164

Kelleher, Ian, Harley, M., Murtagh, A., \& Cannon, M. (2011). Are Screening Instruments Valid for Psychotic-Like Experiences? A Validation Study of Screening Questions for Psychotic-Like Experiences Using In-Depth Clinical Interview, 37(2), 362-369. https://doi.org/10.1093/schbul/sbp057

Kim, S. W., Chung, Y. C., Kang, Y. S., Kim, J. K., Jang, J. E., Jhon, M., ... Yoon, J. S. (2018). Validation of the Korean version of the 16-Item Prodromal Questionnaire in a NonHelp-Seeking College Population. Psychiatry Investigation, 15(2), 111-117. https://doi.org/10.30773/pi.2017.04.24

Kline, E. R., Chokran, C., Rodenhiser-Hill, J., Seidman, L. J., \& Woodberry, K. A. (2019). Psychosis screening practices in schools: A survey of school-based mental health providers. Early Intervention in Psychiatry, 13(4), 818-822. https://doi.org/10.1111/eip.12672

Kline, E., \& Schiffman, J. (2014). Psychosis risk screening: A systematic review. Schizophrenia Research, 158(1-3). https://doi.org/10.1016/j.schres.2014.06.036

Kmet, L. M., Lee, R. C., \& Cook, L. S. (2004). HTA Initiative \# 13. Standard quality assessment criteria for evaluating primary research papers from a variety of fields. HTA Initiative.

Landis, J. R., \& Koch, G. G. (1977). The Measurement of Observer Agreement for Categorical Data. Biometrics, 33(1), 159-174. https://doi.org/10.2307/2529310

Leavey, G., Rothi, D., \& Paul, R. (2011). Trust, autonomy and relationships: The helpseeking preferences of young people in secondary level schools in London (UK). Journal of Adolescence, 34(4), 685-693. https://doi.org/10.1016/j.adolescence.2010.09.004

Levitt, J. M., Saka, N., Hunter Romanelli, L., \& Hoagwood, K. (2007). Early identification of mental health problems in schools: The status of instrumentation. Journal of School Psychology, 45(2), 163-191. https://doi.org/10.1016/j.jsp.2006.11.005

Loewy, R.L., Bearden, C. E., Johnson, J. K., Raine, A., \& Cannon, T. D. (2005). The prodromal questionnaire (PQ): Preliminary validation of a self-report screening measure for 
prodromal and psychotic syndromes. Schizophrenia Research, 77(2-3).

https://doi.org/10.1016/j.schres.2005.02.009

Loewy, R.L., Pearson, R., Vinogradov, S., Bearden, C. E., \& Cannon, T. D. (2011).

Psychosis risk screening with the Prodromal Questionnaire - Brief Version (PQ-B).

Schizophrenia Research, 129(1). https://doi.org/10.1016/j.schres.2011.03.029

Marcelis, M., Navarro-Mateu, F., Murray, R., \& van Os, J. (1998). Urbanization and psychosis: a study of 1942-1978 birth cohorts in The Netherlands. Psychological Medicine, 28(4), 871-879. https://doi.org/10.1017/s0033291798006898

Marshall, M., Lewis, S., Lockwood, A., Drake, R., Jones, P., \& Croudace, T. (2005).

Association between duration of untreated psychosis and outcome in cohorts of first-episode patients: A systematic review. Archives of General Psychiatry, 62(9), 975-983.

https://doi.org/10.1001/archpsyc.62.9.975

Mascayano, F., Armijo, J. E., \& Yang, L. H. (2015). Addressing stigma relating to mental illness in low- and middle-income countries. Frontiers in Psychiatry, 6(MAR), 1-4. https://doi.org/10.3389/fpsyt.2015.00038

Mass, R. (2000). Characteristic Subjective Experiences of Schizophrenia. Schizophrenia Bulletin, 26(4), 921-931. https://doi.org/10.1093/oxfordjournals.schbul.a033506

Miller, T. J., McGlashan, T. H., Rosen, J. L., Cadenhead, K., Ventura, J., McFarlane, W., ... Woods, S. W. (2003). Prodromal Assessment with the Structured Interview for Prodromal Syndromes and the Scale of Prodromal Symptoms: Predictive Validity, Interrater Reliability, and Training to Reliability. Schizophrenia Bulletin, 29(4), 703-715.

https://doi.org/10.1093/oxfordjournals.schbul.a007040

Moher, D., Liberati, A., Tetzlaff, J., Altman, D. G., Altman, D., Antes, G., ... Tugwell, P. (2009). Preferred reporting items for systematic reviews and meta-analyses: The PRISMA statement (Chinese edition). Journal of Chinese Integrative Medicine, 7(9), 889-896. https://doi.org/10.3736/jcim20090918

NHS. (2018). NHS Choices: NHS Screening. Retrieved from https://www.nhs.uk/conditions/nhs-screening/

Norman, R. M. G., \& Malla, A. K. (2001). Duration of untreated psychosis: a critical examination of the concept and its importance. Psychological Medicine, 31(3), 381-400. 
https://doi.org/10.1017/s0033291701003488

Obuchowski, N. A., Graham, R. J., Baker, M. E., \& Powell, K. A. (2001). Ten criteria for effective screening: Their application to multislice CT screening for pulmonary and colorectal cancers. American Journal of Roentgenology, 176(6), 1357-1362. https://doi.org/10.2214/ajr.176.6.1761357

Okewole, A. O., Ajogbon, D., Adeniji, A. A., Omotoso, O. O., Awhangansi, S. S., Agboola, A. A., \& Oyekanmi, A. K. (2015). Psychosis risk screening among secondary school students in Abeokuta, Nigeria: Validity of the Prodromal Questionnaire - Brief Version (PQ-B). Schizophrenia Research, 164(1-3), 281-282. https://doi.org/10.1016/j.schres.2015.01.006 Ord, L. M., Myles-Worsley, M., Blailes, F., \& Ngiralmau, H. (2004). Screening for prodromal adolescents in an isolated high-risk population. Schizophrenia Research, 71(2-3), 507-508. https://doi.org/10.1016/j.schres.2004.03.014

Rickwood, D., Deane, F. P., \& Wilson, C. J. (2007). When and how do young people seek professional help for mental health problems? Medical Journal of Australia, 187(7), 35-39.

Rickwood, D., Deane, F. P., Wilson, C. J., \& Ciarrochi, J. V. (2005). Young people' s helpseeking for mental health problems. Publication Details. Australian E-Journal for the Advancement of Mental Health, 4(3), 1-34.

Sandieson, R. (2006). Pathfinding in research forest: The pearl harvesting method for effective information retrieval. Education and Training in Developmental Disabilities, 41(4), 401-409. https://doi.org/10.2307/23879666

Savill, M., D’Ambrosio, J., Cannon, T. D., \& Loewy, R. L. (2018). Psychosis risk screening in different populations using the Prodromal Questionnaire: A systematic review. Early Intervention in Psychiatry, 12(1), 3-14. https://doi.org/10.1111/eip.12446

van Os, J., \& Guloksuz, S. (2017). A critique of the "ultra-high risk" and "transition" paradigm. World Psychiatry, 16(2), 200-206. https://doi.org/10.1002/wps.20423

van Os, J., Hanssen, M., Bijl, R. V., \& Vollebergh, W. (2003). Prevalence of Psychotic Disorder and Community Level of Psychotic Symptoms. Archives of General Psychiatry, 58(7), 663. https://doi.org/10.1001/archpsyc.58.7.663

Van Voren, R. (2010). Political abuse of psychiatry - An historical overview. Schizophrenia Bulletin, 36(1), 33-35. https://doi.org/10.1093/schbul/sbp119 
Veritas Health Innovation. (n.d.). Covidence systematic review software. Melbourne, Australia.: Veritas Health Innovation. Retrieved from www.covidence.org

Yung, A. R., \& McGorry, P. D. (1996). The Prodromal Phase of First-episode Psychosis:

Past and Current Conceptualizations. Schizophrenia Bulletin, 22(2), 353-370.

https://doi.org/10.1093/schbul/22.2.353

Yung, A., Yuen, H. P., Phillips, L. J., Francey, S. M., \& McGorry, P. D. (2005). Mapping the onset of psychosis: The comprehensive assessment of at risk mental states (CAARMS).

Australian and New Zealand Journal of Psychiatry, 39(December 2004), 964-971.

https://doi.org/10.1016/S0920-9964(03)80090-7

Yung, Alison R., McGorry, P. D., Francey, S. M., Nelson, B., Baker, K., Phillips, L. J., ... Amminger, G. P. (2007). PACE: a specialised service for young people at risk of psychotic disorders. The Medical Journal of Australia, 187(7 Suppl), 43-46.

https://doi.org/yun10343_fm [pii]

Yung, Alison R., Woods, S. W., Ruhrmann, S., Addington, J., Schultze-Lutter, F., Cornblatt, B. A., ... McGlashan, T. H. (2012). Whither the attenuated psychosis syndrome?

Schizophrenia Bulletin, 38(6), 1130-1134. https://doi.org/10.1093/schbul/sbs108

Zachrisson, H. D., Rödje, K., \& Mykletun, A. (2006). Utilization of health services in relation to mental health problems in adolescents: A population based survey. BMC Public Health, 6 , 1-7. https://doi.org/10.1186/1471-2458-6-34 
Table 1. Summary of Included Studies.

\begin{tabular}{|c|c|c|c|c|c|c|c|c|c|c|}
\hline $\begin{array}{l}\text { First } \\
\text { Author }\end{array}$ & Year & $\mathbf{N}$ & Country & $\begin{array}{l}\text { Age } \\
\text { range }\end{array}$ & $\begin{array}{l}\text { Gender (\%) } \\
(\mathrm{M} / \mathrm{F})\end{array}$ & $\begin{array}{l}\text { Educational } \\
\text { setting }\end{array}$ & $\begin{array}{l}\text { Screening } \\
\text { tool }\end{array}$ & $\begin{array}{l}\text { No. of } \\
\text { items }\end{array}$ & $\begin{array}{l}\text { Quality } \\
\text { scoring† }\end{array}$ & Methods \\
\hline Chen et al. & $\begin{array}{l}2014 \\
2016\end{array}$ & 579 & China & $16-22$ & $42.8 / 57.2$ & University & CPQ-16 & 16 & $\begin{array}{l}20 / 22 \\
20 / 22\end{array}$ & $\begin{array}{l}\text { Used a two-stage screening and } \\
\text { assessment process. Screened } 579 \\
\text { participants using PQ-16. Those } \\
\text { scoring above } \geq 6 \text { on symptom score } \\
\text { invited for follow-up assessment ( } \mathrm{n}= \\
54) \text { and group scoring }<6(\mathrm{n}=50) \text { with } \\
\text { SIPS. }\end{array}$ \\
\hline $\begin{array}{l}\text { Chung et } \\
\text { al. }\end{array}$ & 2013 & 1002 & Korea & $13-15$ & Not reported & Junior School & K-ESI & 40 & $19.5 / 22$ & $\begin{array}{l}\text { Used a three stage approach. Mass } \\
\text { screening ( } \mathrm{n}=1002) \text { using Youth Self- } \\
\text { Report (YSR), then secondary } \\
\text { screening using Korean ESI ( } \mathrm{n}=217) \\
\text { for those scoring above cut-off on } \\
\text { YSR. Participants who agreed were } \\
\text { invited to CAARMS interview } \\
(\mathrm{n}=120) \text {. }\end{array}$ \\
\hline Jang et al. & 2019 & 3400 & Korea & $11-36$ & $33.7 / 66.3$ & $\begin{array}{l}\text { Middle school. } \\
\text { High school. } \\
\text { University }\end{array}$ & KPQ-B & 21 & $21 / 22$ & $\begin{array}{l}\text { Used a two-stage process for screening } \\
\text { (PQ-B, then SIPS with a counsellor), } \\
\text { with further follow-up assessment } \\
\text { using SIPS administered by a } \\
\text { psychiatrist face-to-face. } 3400\end{array}$ \\
\hline
\end{tabular}




\begin{tabular}{|c|c|c|c|c|c|c|c|c|c|c|}
\hline & & & & & & & & & & $\begin{array}{l}\text { screened using PQ-B, those scoring } \geq 3 \\
\text { on } P Q-B \text { ( } n=991 \text { ) were invited for } \\
\text { second screening which } n=261 \text { agreed } \\
\text { to. } N=74 \text { suspected of meeting criteria } \\
\text { for psychosis-risk and assessed by } \\
\text { psychiatrist. }\end{array}$ \\
\hline $\begin{array}{l}\text { Kang et } \\
\text { al. }\end{array}$ & 2012 & 1461 & Korea & $15-17$ & $50 / 50$ & High schools & K-ESI & 40 & $21 / 22$ & $\begin{array}{l}\text { Used a two stage process for screening } \\
\text { and assessment of ARMS. } 1461 \\
\text { students screened using ESI, BDI, } \\
\text { LSAS, MOCI. Those scoring above } \\
\text { threshold on one or more of these } \\
\text { measures invited for follow-up } \\
\text { assessment (n=573). N=186 agreed to } \\
\text { follow-up assessment. Assessment } \\
\text { carried out using the Kiddie Schedule } \\
\text { for Affective Disorders and } \\
\text { Schizophrenia for School-Aged } \\
\text { Children (K-SADS) and CAARMS. }\end{array}$ \\
\hline $\begin{array}{l}\text { Kelleher } \\
\text { et al. }\end{array}$ & 2012 & 1131 & $\begin{array}{l}\text { Republic } \\
\text { of Ireland }\end{array}$ & $11-13$ & Not reported & Primary schools & APSS & 7 & $20 / 22$ & $\begin{array}{l}\text { Used a two stage screening and } \\
\text { identification process. Screening } \\
\text { survey ( } \mathrm{n}=1131) \text { across } 16 \text { schools } \\
\text { using APSS. Random sample }(\mathrm{n}=212) \\
\text { drawn from initial sample of those who }\end{array}$ \\
\hline
\end{tabular}




\begin{tabular}{|c|c|c|c|c|c|c|c|c|c|c|}
\hline & & & & & & & & & & $\begin{array}{l}\text { agreed to take part in interview } \\
\text { process. Interview assessments carried } \\
\text { out using K-SADS, modified to } \\
\text { include } 5 \text { positive symptom sections of } \\
\text { the SIPS. }\end{array}$ \\
\hline Kim et al. & 2018 & 2246 & Korea & $>18$ & Not reported & College & KPQ-16 & 16 & $21 / 22$ & $\begin{array}{l}\text { Used a two-stage process. Participants } \\
\text { screened using KPQ-16. Those scoring } \\
\geq 4 \text { on symptom score }(\mathrm{n}=518 \text { ) invited } \\
\text { for further assessment with CAARMS. }\end{array}$ \\
\hline $\begin{array}{l}\text { Okewole } \\
\text { et al. }\end{array}$ & 2015 & 508 & Nigeria & $\begin{array}{l}10^{\text {th }}-12^{\text {th }} \\
\text { grade }\end{array}$ & Not reported & $\begin{array}{l}\text { Secondary } \\
\text { schools }\end{array}$ & PQ-B & 21 & $13 / 22$ & $\begin{array}{l}\text { Used a two stage screening and } \\
\text { identification process. } 508 \text { pupils from } \\
8 \text { secondary schools in Ogun State, } \\
\text { Nigeria completed data for screening } \\
\text { using PQ-B. Random selection of } \\
\text { sample (n=102) were invited for } \\
\text { follow-up SIPS interviews with } \\
\text { Psychiatry trainees. }\end{array}$ \\
\hline $\begin{array}{l}\text { Ord \& } \\
\text { Myles- } \\
\text { Worsley }\end{array}$ & 2004 & 648 & $\begin{array}{l}\text { Republic } \\
\text { of Palau }\end{array}$ & $\begin{array}{l}\text { Not } \\
\text { stated }\end{array}$ & $49 / 51$ & High schools & Y-PARQ & 92 & $7.5 / 22$ & $\begin{array}{l}\text { Used a two stage process; screened } 648 \\
\text { students with Y-PARQ. Those who } \\
\text { scored } \geq 11 / 24 \text { for positive symptom } \\
\text { questions invited for follow-up } \\
\text { interview ( } \mathrm{n}=100 \text { ) and } 56 \text { 'control' }\end{array}$ \\
\hline
\end{tabular}




\begin{tabular}{|l|l|l|l|l|l|l|l|l|l}
\hline & & & & & & & participants. Assessment carried out \\
using K-SADS.
\end{tabular}

Abbreviations: APSS, Adolescent Psychotic Symptom Screener; BDI, Beck Depression Inventory; CPQ-16, Chinese version of the Prodromal Questionnaire-16; K-ESI,

Korean version of the Eppendorf Schizophrenia Inventory; KPQ-16, Korean version of the Prodromal Questionnaire-16; KPQ-B, Korean version of the Prodromal

Questionnaire-Brief; LSAS, Liebowitz Social Anxiety Scale; MOCI, Maudsley Obsessive Compulsive Inventory; PQ-B, Prodromal Questionnaire-Brief; Y-PARQ, Youth

Psychosis At-Risk Questionnaire.

$\dagger$ Quality scoring based on Kmet et al (2004) Quality Assessment; rated out of a possible total score of 22. Quality scoring based on average of two reviewers. 
Table 2. Percentage of total sample size scoring above threshold on screening and assessment criteria for ARMS.

\begin{tabular}{|c|c|c|c|c|c|c|}
\hline $\begin{array}{l}\text { Author } \\
\text { (Year) }\end{array}$ & $\begin{array}{l}\text { Screening } \\
\text { tool used }\end{array}$ & $\begin{array}{l}\text { Screening } \\
\text { strategy } \\
\text { implemented } \\
\text { (Targeted or } \\
\text { universal) }\end{array}$ & $\begin{array}{l}\text { Cut-off threshold } \\
\text { used for follow- } \\
\text { up assessment }\end{array}$ & $\begin{array}{l}\text { Total } \\
\text { number of } \\
\text { participants } \\
\text { initially } \\
\text { screened } \\
\text { (n) }\end{array}$ & $\begin{array}{l}\text { \% of total } \\
\text { sample } \\
\text { scoring above } \\
\text { threshold on } \\
\text { employed } \\
\text { tool }\end{array}$ & $\begin{array}{l}\% \text { of total } \\
\text { sample that } \\
\text { met criteria } \\
\text { for ARMS* }\end{array}$ \\
\hline $\begin{array}{l}\text { Chen (2014; } \\
\text { 2016) }\end{array}$ & CPQ-16 & Universal & $\begin{array}{l}\geq 6 \text { on symptom } \\
\text { score }\end{array}$ & 579 & $9.6 \%$ & $3.5 \%$ \\
\hline $\begin{array}{l}\text { Chung } \\
\text { (2013) }\end{array}$ & K-ESI & $\begin{array}{l}\text { Universal then } \\
\text { targeted }\end{array}$ & $\mathrm{N} / \mathrm{A}$ & 1002 & Not reported & $1 \%$ \\
\hline Jang (2019) & KPQ-B & Universal & $\geq 3$ & 3400 & $40 \%$ & Not reported \\
\hline $\begin{array}{l}\text { Kang } \\
(2012)\end{array}$ & K-ESI & Universal & $\geq 29 \dagger$ & 1461 & $33.6 \%$ & $1.26 \%$ \\
\hline $\begin{array}{l}\text { Kelleher } \\
(2012)\end{array}$ & APSS & Universal & $\mathrm{N} / \mathrm{A}$ & 1131 & N/At & $8.1 \% \S$ \\
\hline Kim (2018) & KPQ-16 & Universal & $\begin{array}{l}\geq 4 \text { on symptom } \\
\text { score }\end{array}$ & 2246 & $23.1 \%$ & $<1 \%$ \\
\hline $\begin{array}{l}\text { Okewole } \\
(2015)\end{array}$ & PQ-B & Universal & N/A & 508 & N/At & Not reported \\
\hline
\end{tabular}




\begin{tabular}{|c|c|c|c|c|c|}
\hline Ord (2004) & Y-PARQ & Universal & $\geq 11 / 24$ & 648 & $15.4 \%$ \\
reported & & & \\
\hline
\end{tabular}

$\dagger$ Kang et al (2012) used the ESI, BDI, LSAS and MOCI at screening stage. They used a cut-off threshold of $\geq 29$ for the ESI, however participants were invited for follow-up if they scored above threshold on one or more of any of the screeners. They do not specify how many scored above threshold on ESI alone.

$\$$ Kelleher et al (2012) \& Okewole et al (2015) did not use a threshold on the PQ-B; selected random sample from total sample.

$\S$ Kelleher et al (2012) reported a prevalence rate of $0.9-8.1 \%$ from their total sample depending on assessment criteria used 
Table 3. Sensitivity and specificity of cut-off scores identified by included studies

\begin{tabular}{|c|c|c|c|c|c|c|}
\hline $\begin{array}{l}\text { First } \\
\text { Author } \\
\text { (Year) }\end{array}$ & Measure & $\begin{array}{l}\text { Recommended } \\
\text { cut-off score } \\
\text { (based on help- } \\
\text { seeking } \\
\text { populations) }\end{array}$ & $\begin{array}{l}\text { Optimal cut- } \\
\text { off score (as } \\
\text { recommended } \\
\text { by study) }\end{array}$ & $\begin{array}{l}\text { Sensitivity } \\
(\%)\end{array}$ & $\begin{array}{l}\text { Specificity } \\
(\%)\end{array}$ & PPV (\%) \\
\hline $\begin{array}{l}\text { Chen } \\
(2016)\end{array}$ & CPQ-16 & $\begin{array}{l}\geq 6 \text { (symptom } \\
\text { score) }\end{array}$ & $\begin{array}{l}\geq 9 \text { (symptom } \\
\text { score) }\end{array}$ & $85 \%$ & $87 \%$ & $63 \%$ \\
\hline $\begin{array}{l}\text { Jang } \\
(2019)\end{array}$ & KPB-B & $\geq 3$ (total score) & $\begin{array}{l}\geq 7(\text { total score }) \\
\geq 22(\text { distress } \\
\text { score })\end{array}$ & $\begin{array}{l}72.2 \% \\
\text { (total) } \\
77.8 \% \\
\text { (distress) }\end{array}$ & $\begin{array}{l}71.4 \% \\
\text { (total) } \\
75 \% \\
\text { (distress) }\end{array}$ & $\begin{array}{l}11.7 \% \\
\text { (total) } \\
14.1 \% \\
\text { (distress) }\end{array}$ \\
\hline $\begin{array}{l}\text { Kim } \\
(2018)\end{array}$ & KPQ-16 & $\begin{array}{l}\geq 6 \text { (symptom } \\
\text { score) }\end{array}$ & $\begin{array}{l}\geq 6 \text { ( symptom } \\
\text { score) } \\
\geq 14 \text { (distress } \\
\text { score) }\end{array}$ & $\begin{array}{l}64.7 \% \\
\text { (symptom) } \\
64.7 \% \\
\text { (distress) }\end{array}$ & $\begin{array}{l}71.2 \% \\
\text { (symptom) } \\
74.6 \% \\
\text { (distress) }\end{array}$ & $\begin{array}{l}13.8 \% \\
\text { (symptom) } \\
15.2 \% \\
\text { (distress) }\end{array}$ \\
\hline $\begin{array}{l}\text { Okewole } \\
(2015)\end{array}$ & PQ-B & $\geq 3$ (total score) & $\geq 8$ (total score $)$ & $\begin{array}{l}\text { Not } \\
\text { reported }\end{array}$ & $\begin{array}{l}\text { Not } \\
\text { reported }\end{array}$ & $\mathrm{N} / \mathrm{A}$ \\
\hline
\end{tabular}

